\title{
A New Steam Assisted Gravity Drainage Process Utilizing Vertical Wells
}

\author{
Mohamed Shirif, Ali Alarbah, Hussameldin Ibrahim, Ezeddin Shirif* \\ Faculty of Engineering, University of Regina, Regina, Canada \\ Email: *ezeddin.shirif@uregina.ca
}

How to cite this paper: Shirif, M., Alarbah, A., Ibrahim, H. and Shirif, E. (2017) A New Steam Assisted Gravity Drainage Process Utilizing Vertical Wells. Natural Resources, 8, 397-409.

https://doi.org/10.4236/nr.2017.86025

Received: April 21, 2017

Accepted: June 10, 2017

Published: June 13, 2017

Copyright (c) 2017 by authors and Scientific Research Publishing Inc. This work is licensed under the Creative Commons Attribution International License (CC BY 4.0).

http://creativecommons.org/licenses/by/4.0/

\begin{abstract}
A novel process utilizing vertical wells to enhance heavy oil recovery during steam assisted gravity drainage has been developed. In the vertical well steam assisted gravity drainage (VWSAGD) process shown in Figure 1, the vertical well includes two production strings which are separated by three packers (one dual and two single packers): the short injection string (SIS) is attached to the bottom of the annulus and completed in the top quarter of the perforated formation, while the long production string (LPS) is attached to the bottom of the production tubing and completed in the bottom quarter of the perforated formation. The new process (VWSAGD) requires an initial startup period (warm-up stage) where the steam is injected into both of the injection strings and production string for a specified period of time of about 14-30 days; then both strings are closed to injection for a specified time period of approximately 7 - 10 days (soaking period). After the initial warm-up and the soaking period, the long production string is opened for production, and the short injection string is opened to continuous steam injection for the rest of the specified simulation time. A commercial simulator (CMG-STAR Simulator) was used to study the performance of the new VWSAGD process. A sensitivity analysis was performed for the grid density, soaking time, steam quality, bottom hole producing pressure, steam injection rate, reservoir thickness, reservoir area, and horizontal to vertical permeability anisotropy. The results of this study have shown that the new VWSAGD process is more preferable for reservoir conditions such as high horizontal to vertical permeability ratio and thick reservoir oil zones.
\end{abstract}

\section{Keywords}

Gravity Drainage Process, Vertical Wells

\section{Introduction}

Cyclic Steam Stimulation known as CSS, was developed and used in Western 
Venezuela in 1959. In Alberta, due to the low mobility of the in situ bitumen, any fluid injection into the oil sands results in problems. This results in the injection pressure having to be increased to a level which is sufficient to part the formation. Denbina et al. (1991) created a two-dimensional, radial, single well numerical model in order to investigate the drive mechanisms of CSS in Cold Lake. They found that the main drive mechanisms are formation compaction, solution gas and fluid expansion. Gravity drainage showed a very small contribution to the amount of oil produced during the first two cycles, but in the following cycles can provide a significant increase in oil production [1].

Beattie et al. (1991) created a reservoir deformation model in order to represent the oil sands dilation and re-compaction which occurs during CSS at Cold Lake [2]. This model can match the injection, production pressures, and flow-back times within reason. The relative permeability hysteresis model provides a simple and effective way of modeling history dependent behavior. The deformation was found to be dominated by pore pressure, rather than stress. Vittoratos et al. (1990) proposed a multi-well CSS process in order to better understand the inter well communication seen in the cold lake area [3]. The impact of steaming strategy on bitumen production was shown by simulations to be insignificant during the early cycles. Walter et al. (2000) performed a study on the poroelastic effects which occurred in cyclic steam stimulation in the Cold Lake deposit [4]. In order to understand the aquifer response, a geomechanical and reservoir model was created (coupled model).

The conventional Steam Assisted Gravity Drainage known as SAGD for short was a concept introduced by Butler et al., 1987/2001. Since gravity alone does not provide an efficient drive to move the heated bitumen to a conventional vertical or deviated well at an economical rate, a pair of horizontal wells are used in addition. Two horizontal well pairs are used in SAGD process. The two are

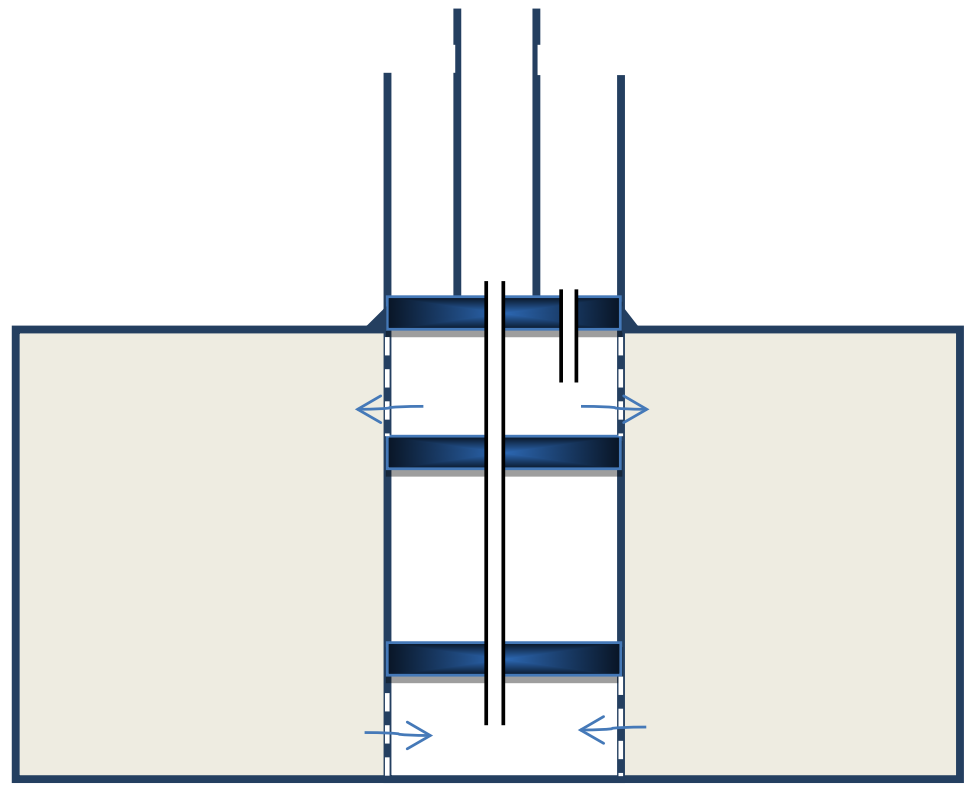

Figure 1. Schematic of vertical well steam assisted gravity drainage process. 
drilled into the lower part of the formation (injector above a producer). Steam circulation is used to heat the both of the wells, as well as the reservoir between the wells. The steam injection continues once communication is established between the two parallel horizontal wells. This results in the formation of a steam chamber, which grows above the injection well in the reservoir. The heated oils and condensate are drained downward by gravity along the sides of the steam chamber into the lower part of the production well. To keep the live steam inside of the reservoir, a steam trap control is created in order to operate the producer at a temperature which is lower than the steam injection temperature by a few degrees which allows for the production of hot oil/bitumen and condensate alone [5] [6] [7].

The newly developed Vertical Well Steam Assisted Gravity Drainage Process (VWSAGD) optimizes the role of gravitational forces, viscosity reduction, and viscous forces during the steam flooding of heavy oils. It is usually applied with a single vertical well. The VWSAGD process is a similar concept to both the conventional SAGD and CSS process. As steam is injected into the reservoir, it causes the reservoir fluids and surrounding rock adjacent to the wellbore to heat up, which allows hot oil and condensed water to flow and drain through by gravitational and viscous forces to a single vertical injection/production well located at the bottom of the formation. For VWSAGD process, heat is transferred into the reservoir by conduction and convection.

\section{Methodology}

To develop an understanding of the new process, we built and compared various simulation runs for VWSAGD process. For the sensitivity analysis, a base case model run was compared against other runs where we varied the grid density, soaking time, steam quality, steam injection rate, bottom hole flowing pressure, reservoir height, reservoir area, permeability anisotropy, as well as the well completion. To achieve the stated objective, Computer Modeling Group's (CMG) STARS Thermal Simulator was used to perform all tasks proposed in this study.

\subsection{Description of the Numerical Model}

The numerical model data used for this study is based on CMG's STARS release 2015 case study, stspe001.dat. The reservoir rock and fluid properties as well as the thermal properties of rock/fluids represent a typical heavy oil reservoir of Lloydminster in Alberta, Canada. The CMG's stspe001.dat case study is a 2-Dradial model used for simulating the CSS process. The reservoir radial geometry was converted to a 3-D Cartesian model in order to simulate the horizontal and vertical wells. The well operating conditions and well completion were also modified substantially to develop additional cases for VWSAGD process.

The grid system and dimensions for simulating the VWSAGD process is shown in Figure 2. The 3-D Cartesian grid models represent a homogeneous reservoir with dimensions $49 \times 49 \times 20$ with local grid refinement around the wellbore. 


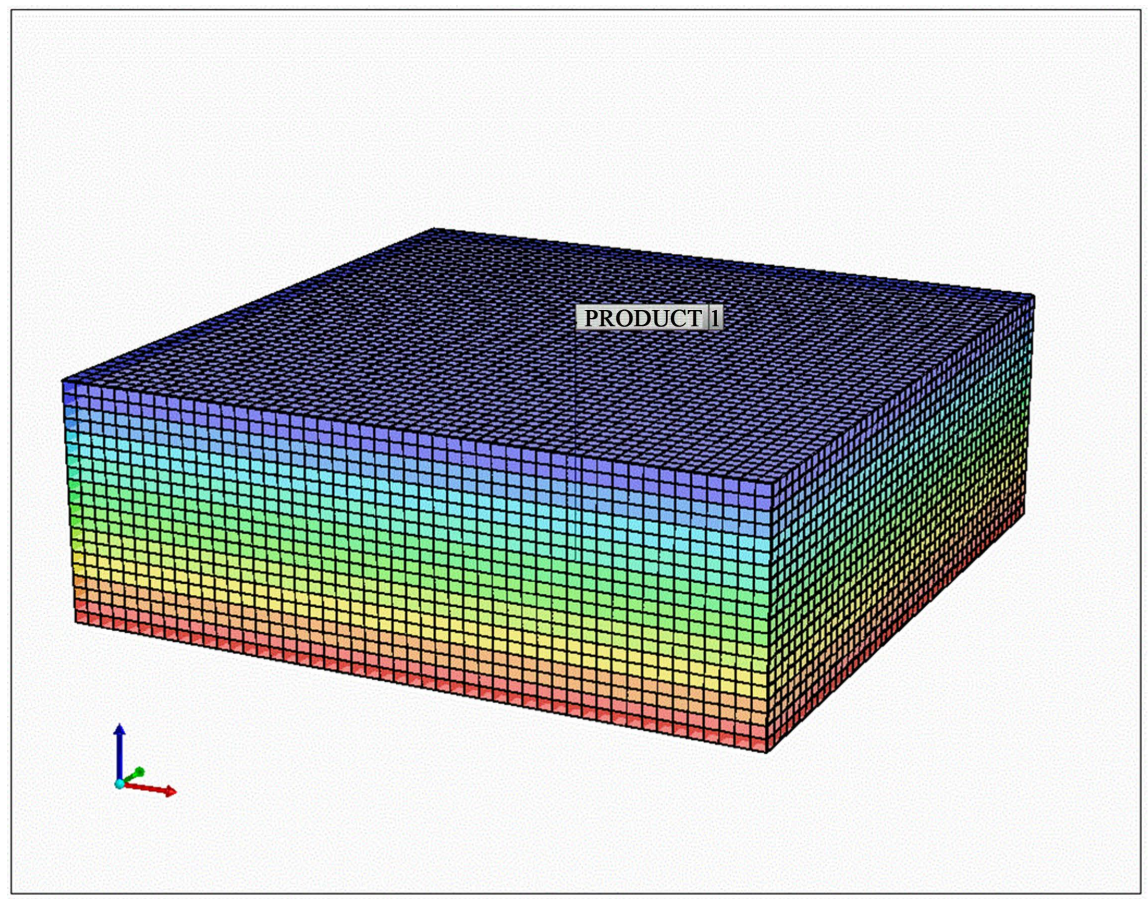

Figure 2. 3-D cartesian model grid system for simulating VWSAGD process.

\subsection{Reservoir Properties}

The relevant reservoir property data are taken from CMG's stspe001.dat case study. A summary of the reservoir model properties for all Runs are shown in Table 1.

\subsection{Relative Permeability}

The reservoir model used is a water-wet sandstone media. The relative permeability data which were used in this study are based on the CMG stspe011.dat case study. The relative permeability is generated using correlations proposed by Honarpour et al. (1986) [8]. The two phase water oil relative permeability as a function of water saturation and the two phase gas oil relative permeability as a function of oil saturation are shown in Figure 3 and Figure 4 respectively. The three phase relative permeability was generated using Stone's model.

\subsection{Heavy Oil Viscosity Model}

The oil viscosity used for this study is generated by the experimental method. The dependence of oil viscosity on temperature is shown in Figure 5.

\subsection{Base Model}

The 3D-Cartesian grid base model for VWSAG process has dimensions $49 \times 49$ $\times 20$. The total number of grid blocks is 49020 . The VWSGAD base models are shown in Figure 2. The reservoir base model is homogenous with a single porosity of $30 \%$, horizontal permeability $\left(\mathrm{k}_{\mathrm{H}}=\mathrm{k}_{\mathrm{x}}=\mathrm{k}_{\mathrm{y}}\right)$ of $1500 \mathrm{md}$, and vertical permeability of $500 \mathrm{md}$. The connate water saturation is $45 \%$, and initial oil saturation is $55 \%$. Initial oil in place is $2,897,500 \mathrm{ft}^{3}(516,028 \mathrm{bbl})$. Initial reservoir 


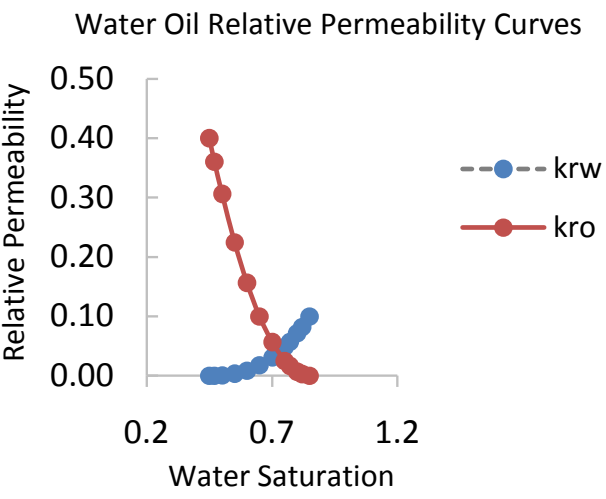

Figure 3. Two phase water oil relative permeability.

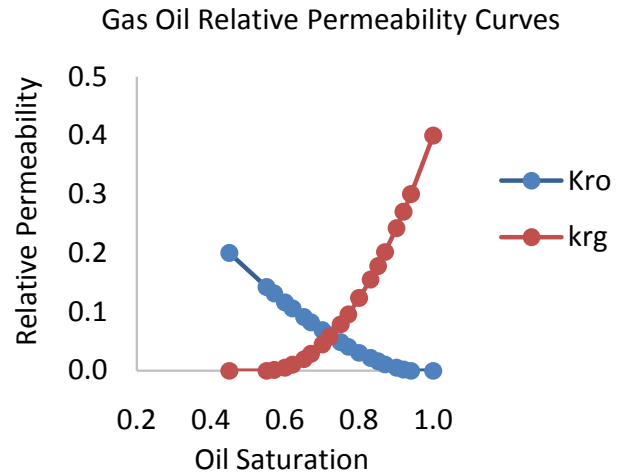

Figure 4. Two phase gas oil relative permeability.

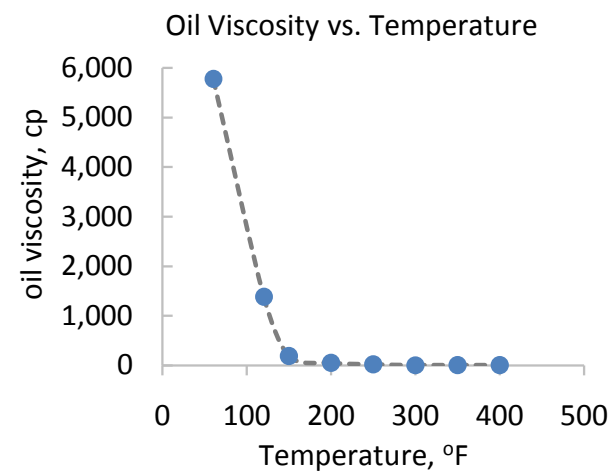

Figure 5. Dependence of dead oil viscosity on temperature.

Table 1. Reservoir physical properties.

\begin{tabular}{cccc}
\hline Reservoir area, (Acre) & $5-30$ & Initial oil saturation, (\%) & 55 \\
Reservoir thickness, (ft) & $20-200$ & Reservoir porosity, (\%) & 30 \\
Initial water saturation, (\%) & 40 & Oil viscosity at SC, (cp) & 5780 \\
Initial reservoir pressure, (psia) & 17 & Oil molecular weight & 600 \\
Initial reservoir temperature, $\left({ }^{\circ} \mathrm{F}\right)$ & 120 & Oil mass density (lb/cf) & 60.678 \\
Vertical permeability, (md) & $100-1500$ & Standard pressure, (psia) & 14.7 \\
Horizontal permeability, (md) & 1000 & Standard temperature, $\left({ }^{\circ} \mathrm{F}\right)$ & 60 \\
Formation compressibility, (1/psia) & $5 \times 10^{-4}$ & & \\
\hline
\end{tabular}


pressure of $75 \mathrm{psia}$, and a temperature of $125^{\circ} \mathrm{F}$. The dead oil density and viscosity are approximately $60.678 \mathrm{lb} / \mathrm{cf}$ and $5780 \mathrm{cp}$ respectively. The base model operating conditions and other relevant parameters are listed in Table 2.

\subsection{Well Data}

For the VWSAGD process, the single vertical well is located at the center of the reservoir $(25,25$, and 1$)$ and goes through the entire reservoir thickness. The short injection string (SIS) is assigned at top quarter of the perforation and the long production string (LPS) is assigned at bottom quarter of the perforation.

A five year simulation time was chosen for all of the runs. The simulation starts at 2015-01-01 and finishes at 2021-1-1. Before the start of the simulation period for the base models, a period of 20 days was selected as the duration of the startup period flowed by 10 days as the soak period. The reservoir temperature distributions at the end of simulation time for both processes are shown in Figure 6.

\section{Results and Discussion}

\subsection{Optimization of the Grid Density}

For this study, we selected five grid sizes, and the simulation results are presented in Table 3 . Based on the results, it is clear that the optimum grid size is $49 \times 49 \times 20$

Table 2. Base model properties description.

$\begin{array}{cc}\text { Reservoir area, (Acre) } & 5 \\ \text { Reservoir Thickness, (ft) } & 80 \\ \text { Vertical permeability, (md) } & 500 \\ \text { Horizontal permeability, (md) } & 1000 \\ \text { Initial reservoir pressure, (psia) } & 75 \\ \text { Steam quality } & 0.7 \\ \text { Steam injection rate, (cwe), (bbl/day) } & 1000 \\ \text { Maximum steam injection pressure (psia) } & 1000 \\ \text { inimum bottom hole producing pressure, (psia) } & 17\end{array}$

Table 3. Optimization of grid block density.

\begin{tabular}{cc}
\hline Model Dimensions & Cumulative Recovery at 1 PV of Steam Injection, bbl \\
\hline $19 \times 19 \times 20$ & 47,758 \\
$29 \times 29 \times 20$ & 49,152 \\
$39 \times 39 \times 20$ & 51,865 \\
$49 \times 49 \times 20$ & 52,255 \\
$59 \times 59 \times 20$ & 52,261 \\
$69 \times 69 \times 20$ & 52,265 \\
\hline
\end{tabular}




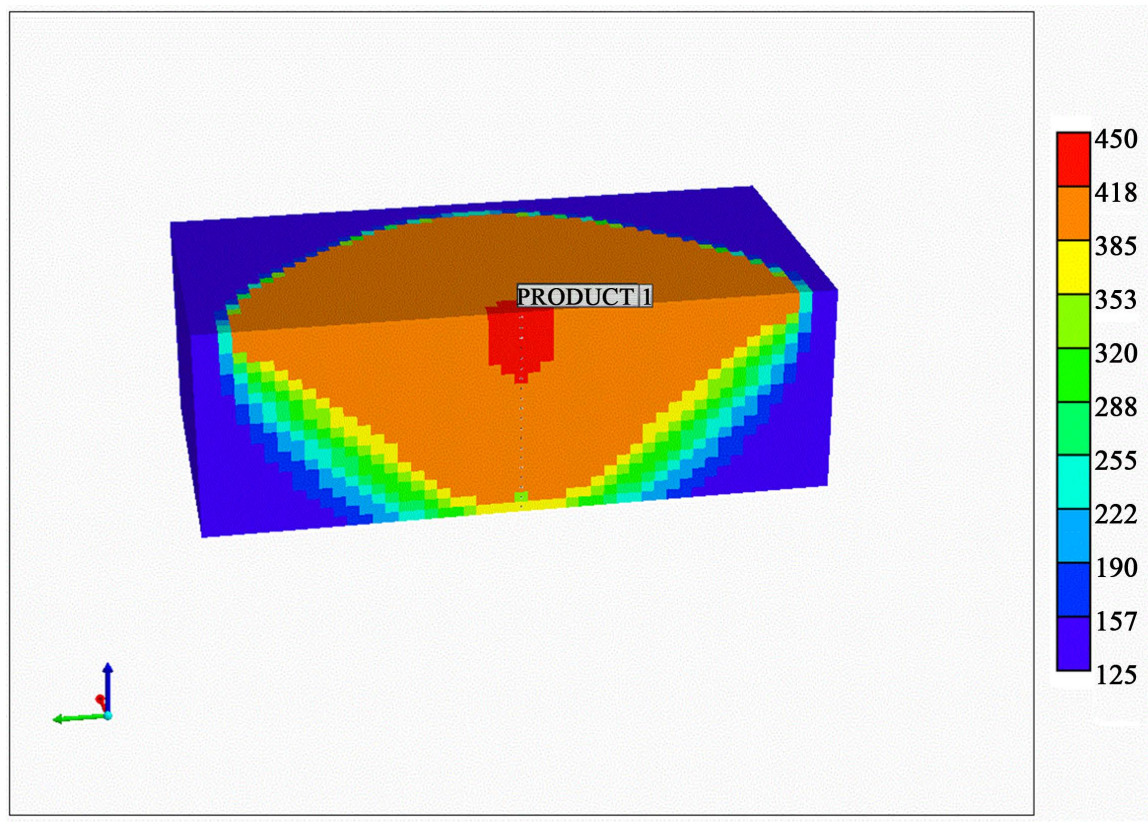

Figure 6. VWSAGD temperature distribution.

\subsection{Optimization of Reservoir Perforation}

For the base run in this study, the reservoir thickness was selected to be $80 \mathrm{ft}$, and the question posed was what are the optimum perforation zone for the short injection string, and the long production string. In order for us to optimize the perforation of the 2 strings, 23 simulation runs were conducted to calculate the optimum intervals which will give us the lowest steam oil ratio, lowest water oil ratio and maximum cumulative oil recovery. Table 4 summarizes five of those runs. It has been found that perforating the top quarter of the reservoir for the short injection string, and the bottom quarter of the reservoir for the long production string were the optimum perforations for this study.

\section{Sensitivity Studies}

\section{Effect of Vertical Permeability}

The effect of the vertical permeability for vertical well SAGD process is presented in Figures 7-10. Figure 7 shows the effect of the permeability on the cumulative oil production. It is clear that as the vertical permeability increases, the cumulative oil production decreases. The results show that the oil recovery is driven by gravitational forces, as well as viscous forces. As the vertical permeability increases and the reservoir oil is being heated enough so that the viscosity is decreased, the gravitational forces become more dominant. As a result of the increase in vertical communication, steam and condensed hot water will flow more freely towards the production string. This results in low oil recovery. Figure 9 and Figure 10 shows that as the vertical permeability increases, the steam oil ratio and water oil ratio will increase which support the conclusion stated above.

\section{Effect of Reservoir Thickness}


VWSAGD: Effect of Vertical Permeability on Cumulative Oil Recovery

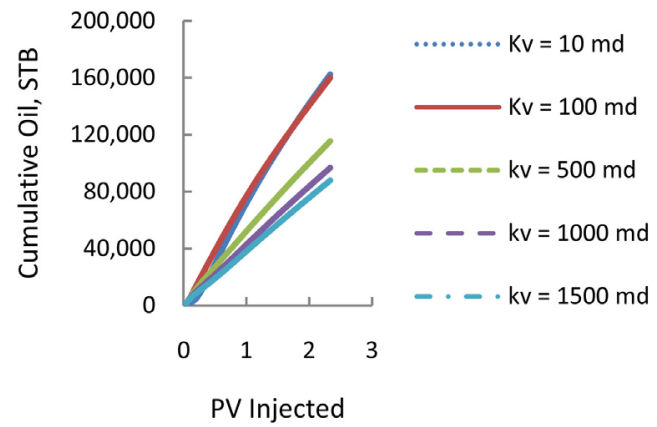

Figure 7. Effect of vertical permeability on cumulative oil recovery.

VWSAGD: Effect of Vertical Permeability on Oil Production Rate

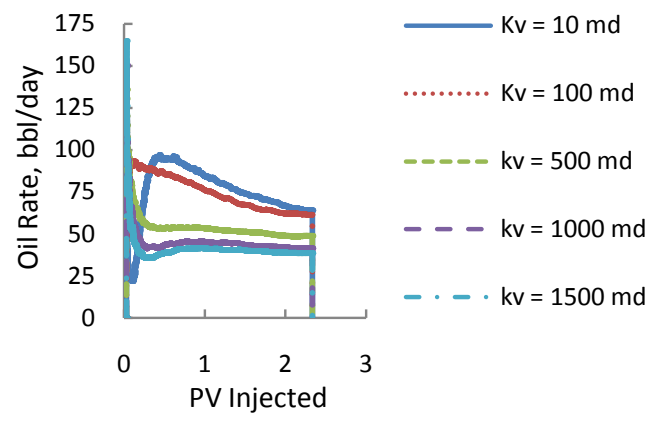

Figure 8. Effect of vertical permeability on oil production rate.

VWSAGD: Effect of Vertical Permeability on SOR

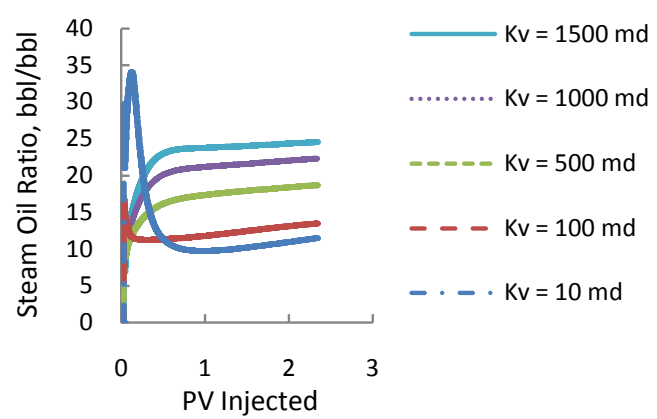

Figure 9. Effect of vertical permeability on steam oil ratio.

Table 4. Optimization of penetration interval.

\begin{tabular}{ccc}
\hline Top Injection Interval/Bottom Production Interval, $\mathrm{ft}$ & Steam Oil Ratio & Water Oil Ratio \\
\hline $10 / 10$ & 10.22 & 10.63 \\
$20 / 20$ & 6.25 & 5.95 \\
$30 / 30$ & 17.45 & 18.86 \\
$40 / 40$ & 66.35 & 68.69 \\
$50 / 50$ & 413.48 & 319.14 \\
\hline
\end{tabular}


VWSAGD: Effect of Vertical Permeability on WOR

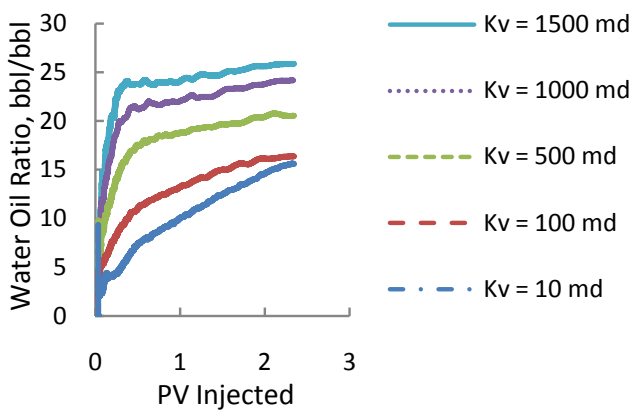

Figure 10. Effect of vertical permeability on water oil ratio.

Figure 11 shows the effect of increasing the reservoir thickness on the cumulative oil recovery. It is clear that as the reservoir thickness increases, the cumulative oil recovery increases as well. Figure 12 and Figure 13 shows that the oil production increases as reservoir thickness increases. This increase in oil recovery is supported by the increase in the initial oil in place due to the increase in reservoir thickness, as well as due to a decrease in the steam oil ratio and water oil ratio As the reservoir thickness increases, it requires more steam injection into the reservoir, and the amount of liquid produced will increase as well.

\section{Effect of Reservoir Area}

As the reservoir area increases, the initial oil in place will increase as well. The amount of steam injected is constant for all area sizes. This means that the same amount of steam is injected for a reservoir with an area of 5 acres, and a reservoir with an area of 30 acres. In Figure 14, the cumulative oil recovery decreases as the area increases. This reduction is due to the limited amount of steam injected in all areas. Figure 15 supports the previous results, and shows that the oil rate decreases as the reservoir area increases. Figure 16 and Figure 17 show that the steam oil ratio and the water oil ratio increase as the reservoir area increases. This finding supports the previous fact that a decrease in the oil recovery rate results in an increase in the steam and water produced.

\section{Effect of Heating/Soaking period}

The effect of the Heating/Soaking period on the oil recovery is shown in Figures 18-21. Figure 18 shows the effect of the soaking period on the cumulative oil recovery. It is clear from Figure 18 that as the soaking period increases, it has no effect on the cumulative oil recovery. This is because when steam is injected in the start-up period in order to heat the formation, the entire area surrounding the production and injection string are heated evenly, and the communication between the production and injection string were instantaneous. This phenomena opposes the conventional SAGD process, which requires a heating period of up to two months in order to establish communication between the two horizontal wells (injector and producer). Figures 19-21 show the effect of the heating period on oil rate, steam oil ratio and water oil ratio. It is clear that the heating period has minimal effect on the cumulative oil recovery, steam oil ratio and water oil ratio. 


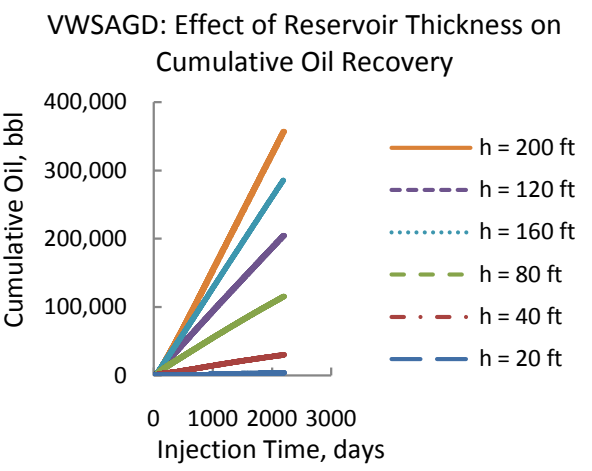

Figure 11. Effect of reservoir thickness on cumulative oil recovery.

\section{VWSAGD: Effect of Reservoir thickness on Oil Production Rate}

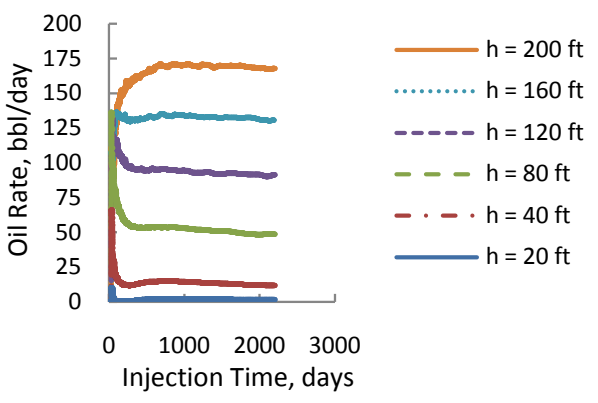

Figure 12. Effect of reservoir thickness on oil production.

VWSAGD: Effect of Formation Thickness on SOR

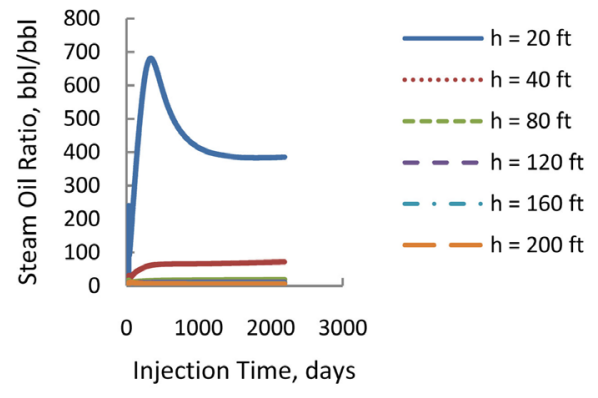

Figure 13. Effect of formation thickness on steam oil ratio.

\section{VWSAGD: Effect of Reservoir Area Size on} Cumulative Oil Recovery

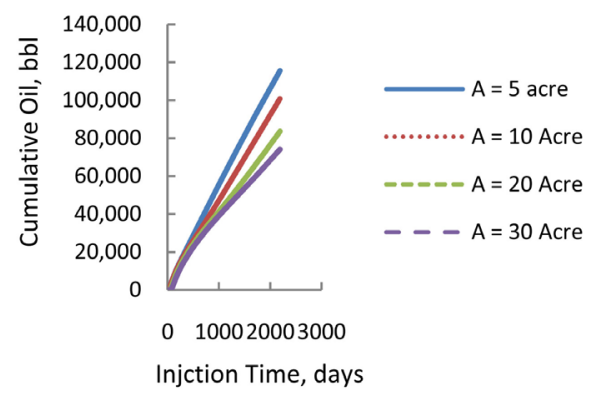

Figure 14. Effect of reservoir area size on cumulative oil recovery. 
VWSAGD: Effect of Reservoir Area Size on Oil Production Rate

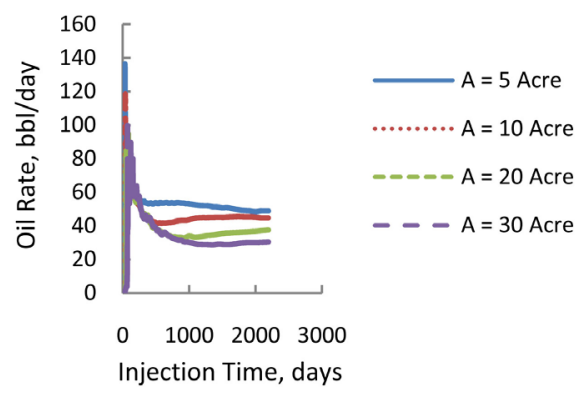

Figure 15. Effect of reservoir area size on oil production rate.

VWSAGD: Effect of Reservoir Area Size on SOR

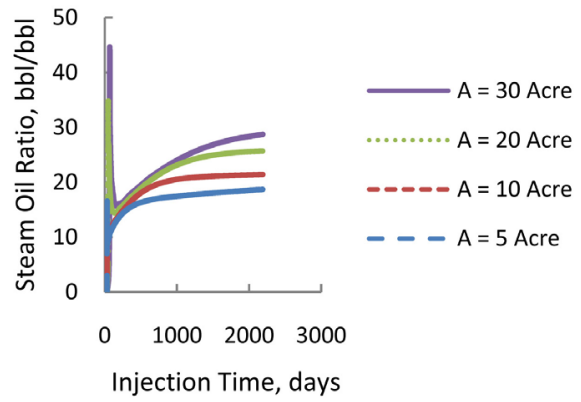

Figure 16. Effect of reservoir area size on steam oil ratio.

VWSAGD: Effect of Reservoir Area Size on

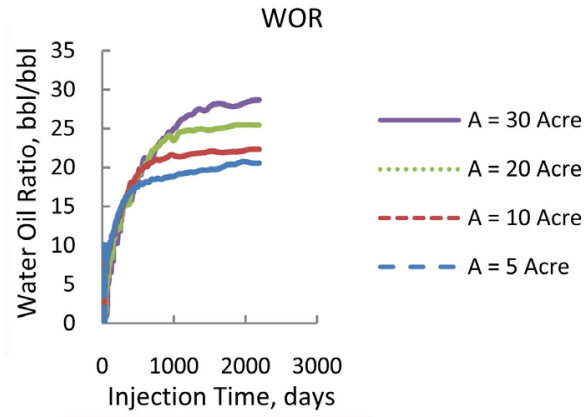

Figure 17. Effect of reservoir area size on water oil ratio.

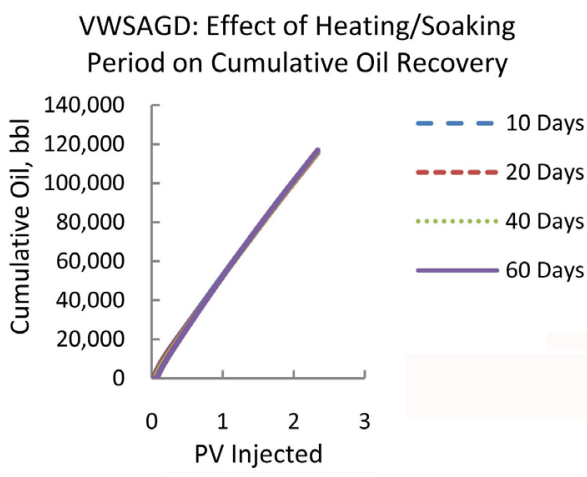

Figure 18. Effect of heating/soaking period on cumulative oil recovery. 


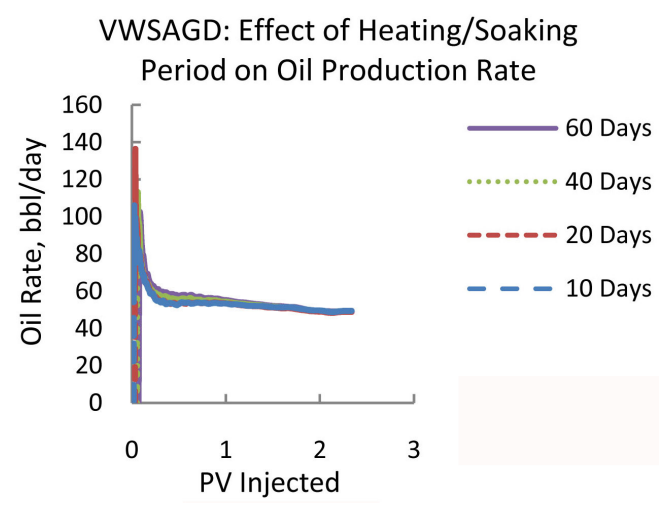

Figure 19. Effect of heating/soaking period on oil production rate.

VWSAGD: Effect of Heating/Soaking Period on SOR

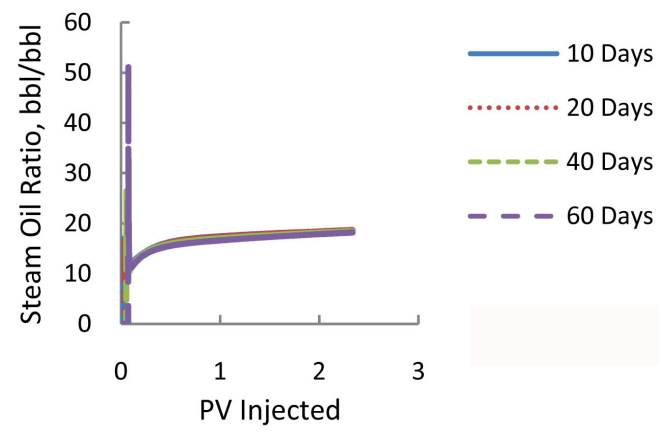

Figure 20. Effect of heating/soaking period on steam oil ratio.

$$
\text { VWSAGD: Effect of Heating/Soaking }
$$

Period on WOR

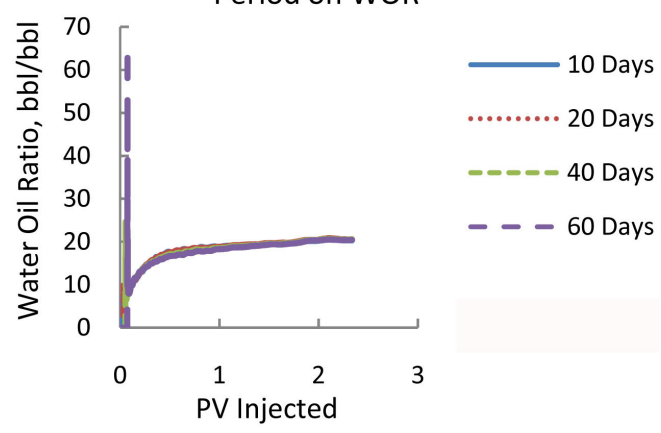

Figure 21. Effect of heating/soaking period on water oil.

\section{Conclusions}

Based on this research study, we can conclude the following:

1) A new process (VWSAGD) for steam assisted gravity drainage utilizing vertical wells has been presented. The process was optimized and tested. This new process has shown very promising results.

2) As the reservoir thickness increases, the new process is more suitable and gives better results.

3) As the reservoir vertical permeability decreases, the vertical well SAGD is more shown better oil recovery. 


\section{Acknowledgements}

The authors gratefully acknowledge the unlimited financial support of the Faculty of Graduate Studies and Research at the University of Regina.

\section{References}

[1] Denbina, E.S., Boberg, T.C. and Rotter, M.B. (1991) Evaluation of Key Reservoir Drive Mechanisms in the Early Cycles of Steam Stimulation at Cold Lake. SPE Reservoir Engineering, 6. https://doi.org/10.2118/16737-PA

[2] Beattie, C.I., Boberg, T.C. and McNab, G.S. (1991) Reservoir Simulation of Cyclic Steam stimulation in the Cold Lake Oil Sands. SPE Reservoir Engineering, 6. https://doi.org/10.2118/18752-PA

[3] Vittoratos, E., Scott, G.R and Beattie, C.I. (1990) Cold Lake Cyclic Steam Stimulation: A Multi-Well Process. SPE Reservoir Engineering, 5. https://doi.org/10.2118/17422-PA

[4] Walters, D.A., Settari, A. and Kry, P.R. (2000) Poroelastic Effects of Cyclic Steam Stimulation in the Cold Lake Reservoir. SPE 62590 Presented at the SPE/AAPG Western Regional Meeting, Long Beach, 19-23 June 2000.

[5] Butler, R.M. (1987) Rise of Interfering Steam Chambers. Journal of Canadian Petroleum Technology, Paper 87-03-07, June 1987.

[6] Butler, R.M. (1998) SAGD Comes of AGE. Journal of Canadian Petroleum Technology, 37. https://doi.org/10.2118/98-07-DA

[7] Butler, R.M. (2001) Some Recent Development in SAGD. Journal of Canadian Petroleum Technology, 40. https://doi.org/10.2118/01-01-DAS

[8] Honarpour, M., Koederitz, L. and Harvey, A.H. (1986) Relative Permeability of Petroleum Reservoirs. CRC Press, Boca Raton, 16-41.

Submit or recommend next manuscript to SCIRP and we will provide best service for you:

Accepting pre-submission inquiries through Email, Facebook, LinkedIn, Twitter, etc. A wide selection of journals (inclusive of 9 subjects, more than 200 journals)

Providing 24-hour high-quality service

User-friendly online submission system

Fair and swift peer-review system

Efficient typesetting and proofreading procedure

Display of the result of downloads and visits, as well as the number of cited articles

Maximum dissemination of your research work

Submit your manuscript at: http://papersubmission.scirp.org/

Or contact nr@scirp.org 